\title{
La correspondencia familiar del conde de Rius
}

\author{
ASUNCION DIEZ LOPEZ *
}

La figura de Mariano Rius Montaner, conde de Rius, es poco conocida entre los especialistas en el siglo XIX. Sin embargo no carece de interés, debido a dos aspectos fundamentales: el primero, el ser un buen representante de la alta burguesía de provincias, más tarde ennoblecida, que ocupando un puesto político en Madrid, emplea su influencia para impulsar el desarrollo de su ciudad natal; el segundo, y más ignorado, es que se trata, probablemente, del único amigo personal que tuvo el rey Amadeo durante su estancia en España.

\section{APUNTE BIOGRÁFICO}

Mariano Rius nació en Tarragona el 19 de agosto de 1835, de una familia de hacendados. Hacia 1853 se desplaza a Madrid para estudiar Leyes, y es en la capital donde entra en contacto con los progresistas, más exactamente con la facción que lidera Salustiano de Olózaga. Su relación con Olózaga se va estrechando hasta que en 1864 contrae matrimonio con la hija de éste, Elisa.

Los sucesos de 1866, que acarrean el destierro de su suegro, coinciden con la muerte de Elisa ${ }^{1}$ al dar a luz a la única hija del matrimonio,

* UNED.

- La lberia, publica el 24-3-1866, una poesia, bastante mediocre, de Concepción Arenal, "A mi afligido amigo don Salustiano de Olózaga", consolándolo por la muerte de su hija. 
María Elisa, y, si bien no consta que Rius fuera también desterrado, el hecho es que éste se retira a Tarragona, donde participa activamente en la revolución de 1868 .

Es en esta fecha, cuando comienza la carrera pública de Rius, siendo vicepresidente de la Junta Revolucionaria de Tarragona y, a continuación, presidente de la Diputación. Su primer acta de Diputado la obtiene en las elecciones de 1869, por la circunscripción de Tortosa ${ }^{2}$.

Es nombrado Secretario de las Cortes Constituyentes y como tal forma parte de la comisión que viaja a Italia para ofrecer la corona a Amadeo de Saboya. Sin duda es con ocasión de este viaje cuando se entabla la amistad entre ambos, que hace que, cuando Amadeo visite Tarragona en septiembre de 1870 , se aloje en casa de Rius, favor éste sumamente particular.

Amadeo le nombra mayordomo mayor, cargo que ostentará hasta el fin del reinado, y le otorga el título de conde de Rius.

Cuando Amadeo renuncia a la corona, en febrero del 73. Rius forma parte del reducido séquito que, encabezado por Ruiz Zorrilla, acompaña al monarca hasta Lisboa, pero el Conde de Rius, ya tan sólo a título de amigo, continuará, como único acompañante español, hasta Turín.

El Conde de Rius había sido elegido diputado por Falset en las Cortes de 1872 y lo será de nuevo en las primeras Cortes de la Restauración y en las de 1881, pero no jurará el cargo por lealtad a Amadeo. No será hasta 1883, diez años después de la renuncia del de Saboya, cuando Rius reconozca a la monarquía borbónica.

Será diputado en todas las legislaturas posteriores, como miembro del partido fusionista, la última la de 1893, murieron en 1894 a la edad de 56 años.

A su influencia se debe el puerto de Tarragona, el puente sobre el Francoli, la estación del ferrocarril, diversas carreteras de la provincia y otras obras urbanas.

${ }^{2}$ Los diputados por la Provincia de Tarragona son cinco en total, pero, en esa fecha, Rius debia ser prácticamente desconocido para sus paisanos, ya que, en el periódico satírico Lo que passa, aunque en la caricatura de portada del número 12 de 24-1-1869, aparecen los cinco diputados, en las letrillas que recogen las aspiraciones de la provincia, no se citan más que a cuatro: “La provincia de Tarraco/provincia de catalans/demana to que segueix/ als seus quatre diputats..". Esos cuatro diputados son Prim, Pedro Mata, Celestino Olózaga y Federico Gomis. 


\section{LAS CARTAS FAMILIARES}

Las cartas inéditas que aquí se recogen están escritas entre 1876 y 1893, formando el cuerpo principal veinte escritas por su hija María Elisa, en enero de 1888. La primera, escrita por la madre de Rius, y la última, escrita por un sacerdote de Tarragona, se incluyen por haber sido guardadas en el mismo legajo que las otras, presumiblemente por el mismo conde de Rius, marcando de este modo una cierta relación entre ellas ${ }^{3}$.

El caracter privado de esta correspondencia le confiere un caracter testimonial en cuanto a la vida cotidiana de una clase social. Algunos aspectos merecen ser señalados: el primero y más evidente, es que toda la correspondencia se realiza en castellano, incluso la breve nota de mano del yerno de Rius ${ }^{4}$; el segundo, la existencia de un fuerte clientelismo, que se refleja implicitamente en el desfile de visitas que frecuentan a Maria Elisa y explícitamente mencionado en las cartas 15 y 17; el tercero, es la relación paternofilial, más estrecha que lo usual en la época, posiblemente debido a la prematura muerte de la madre; paralelamente, llama la atención la ligereza de la mención de María Elisa, en la carta 13, a la niña muerta al nacer ${ }^{5}$, ligereza que es reflejo de la posición secundaria de los niños hasta su llegada al uso de razón; por último, de distintas alusiones, se desprende el carácter melancólico de Rius, más que justificado, por otra parte, por las sucesivas pérdidas que sufre.

Las cartas se transcriben con la grafía original.

\section{CARTA NUMERO 1}

Tarragona 12 de Julio de 1876.-Mi estimado ${ }^{6}$ Mariano: he visto con mucho gusto tu apreciable fecha 7 del que rige, en la que me anuncias

${ }^{3}$ Estas cartas se encontraban en poder de la familia Sanmarti, de Tarragona, por motivos difíciles de determinar.

${ }^{4}$ Fernando Querol, abogado y literato, tiene varios escritos en catalán, entre ellos su novela Els Porpras.

${ }_{5}$ Probablemente, la enfermedad que menciona ella en sus cartas, está motivada por el parto de esa niña.

"Este "estimado" no es tan formal como pudiera parecer, ya que lo más probable es que tenga sentido del "estimat" catalán, es decir, "amado". 
tu proxima salida de esa para Lequeitio con Ma. Elisa, y la resolucion has tomado(sic) de que esta á instancia suya y de sus profesoras vuelva á ingresar en el mismo colegio por Setbre. (Dios mediante). El mal rato que me proporcionaba no traerla en esta, me lo ha hecho pasar el que la hagas seguir otro año en el referido colegio: tales son mis deseos de que la niña reciba una educacion completa. Me he enterado de las notas ha obtenido (sic) este curso, y tanto ami (sic) como á los demas, nos ha parecido que no se puede apetecer mas de una criatura que aun no ha cumplido 11 años de edad.

En cuanto á lo de Scala Dei. estoy conforme en todo á lo que me propones, y muy particularmente á lo del mayodormo, porque como tu creo que de ningun modo nos conviene, y tambien me presumo que la mayor parte de culpa de que este haya obrado mal, la tiene el alcahuete de Benet, porque sí este cumpliera con su obligacion de anunciarnos á tiempo ciertas faltas de los mayordomos, estos no pasarian tan adelante en obrar mal. Por lo mismo, firme á ellos. El secreto de tus pensamientos respecto a este punto, está en la seguridad que solo está entre tu, yo y el capellan.

La cartita me dirige Ma. Elisa nos ha dejado muy satisfechos: es todo lo que puede hacer.

Lo que siento mucho y deseo vivamente se desvanezca de tu imaginacion es, el mal humor que se ha apoderado de tu corazon. Al oir de tí estas cosas, figurate el gusto que me pueden dar, y por lo mismo te suplico que hagas los medios necesarios para distraerte, y tomar las cosas de otra manera. Espero pues que respecto a este punto haras lo posible, aunque no sea más que para darme gusto.

Si Dios nos lo permite, sea cuando fuere que regresemos a Scala Dei, te prometo, puesto que tengo la resolucion formada, acompañarte a Madrid y permanecer algun tiempo en vuestra compañía, te lo anticipo para proporcionarte un buen ratito.

Sin mas que muchos besos de mí parte á mi estimada Nietecita y con cariñosos recuerdos del capellan y familia, ya sabes 10 mucho que te quiere tu madre que te manda un apretado abrazo.-Vicenta.

\section{CARTA NUMERO 2}

Tarragona 2 de Enero de 1888.-Mi muy querido Papá.-Anoche tuve el gusto de recibir la tuya, alegrandome su contenido. 
Yo gracias á Dios estoy muy bien y sigo teniendo apetito. Los Moreras me han hecho compañia toda la tarde y te probará que estoy bien, el que he jugado al tresillo.

Si tu quieres Antonio se casará el sábado y el domingo irá á esa.

Adios papá, son las seis y me voy á la cama. Ya empiezo á tener mas fuerza en las piernas. Recuerdos de todos y un millar de besos de tu hija que mucho te quiere y no te olvida.-María Elisa.-Escribeme todos los días.

Querido Papá: acaba de acostarse Ma. Elisa, y de recibir la visita del Dr. Piquer que está perfectamente.

Opina que no existe ya el tumor y que se puede cerrar paulatinamente el vegigatorio, y siendo esta tambien la opinion de Rovira, esperamos que se ponga bueno Mir para dar enteramente de alta a la enferma.

Los Papás le saludan así como su affmo. Fernando.

CARTA NUMERO 3

Tarragona 4 de Enero 1888.-Mi querido Papá: anoche ya dormia cuando se recibió tu carta fecha 2, pero esta mañana he tenido el gusto de leer que continuas bien de salud, y esta es la mejor noticia que puedo recibir y mas ambiciono. Yo sigo muy bien, gracias a Dios y no debes tener ningun cuidado por mí; tomo todas las precauciones que tu me encargas y no salgo para nada del cuarto. Despues que Rovira me cura y luego me levanto y viene la peinadora; ya puedes figurarte que cabeza tengo, ni en ocho dias se me desenreda el pelo, porque para no marearme solo me arregla un poco cada dia. Apetito tengo bastante y hoy tambien, D.M., cenaré levantada. Toda la tarde me he entretenido arreglando mis papeles porque ya me canso de hacer el chopo.

Gracias de los pensamientos que se conoce eran muy grandes.

El Tesorero y demas amigos me encargan te salude, lo mismo que el tío y los papás. 
Ahora soy yo la que digo que tomes precauciones; sino tranquila del todo to estoy algo porque supongo que Alvaro te acompaña siempre y cerrais bien las puertas ${ }^{7}$.

En tu cuarto te dejaste la sortija; quieres que te la envie con Antonio, que como te decía en una de mis anteriores irá á esa el domingo.

Te reitero papá que no pases cuidado por mí, porque estoy muy bien y Fernando me cuida mucho, recibe sus afectos y deseando y esperando que no podrás pasar mucho tiempo sin verme, como me sucede á mí, te abraza una y mil veces tu hija que te quiere de corazon.-Maria Elisa

Tarragona 6 de Enero 1888.-Mi querido Papá: he recibido esta mañana tu grata de anteayer que me ha tranquilizado pues temia que el silencio del dia anterior fuese por estar indispuesto. Por mi papá no pases cuidado porque estoy muy bien y tomo todas las precauciones que me encargas; no tan solo no voy á la sala que ni siquiera salgo del cuarto, asi es que ya me voy cansando de esta vida tan reposista.

Anoche vino Piquer y opina que ya estoy completamente bien; no asi Mir pues dice hay todavia induracion así es que para que no se cierre el vegigatorio, tiene tendencia á ello, me ponen papeles fuertes, que afortunadamente no me hacen daño.

Anteayer noche vinieron las Canals, Dolores á despedirse, ayer se fué á Bañeras, todos me encargaron te saludara, lo propio que Morera, Maria y la Serrahima, que han estado aquí esta mañana.

Recuerdos de Fernando y sus padres y te envia un millon de besos y abrazos, tu hija que mucho te quiere y desea verte cuanto antes.-Maria Elisa

Nada me dices del vino. No es buena clase?

${ }^{7}$ Para que no haya corrientes de aire. 


\section{CARTA NÚMERO 5}

Tarragona 7 de Enero de 1888.-Mi querido Papá: hoy me he quedado sin carta tuya, esperando el correo de mañana, para ver si soy más afortunada y recibo noticias tuyas. Mias te las puedo dar buenas, porque gracias a Dios continuo bien, tengo apetito y caso ando ya sola. Mañana ya te dirá Antonio que empiezo á parecer otra, porque voy engordando algo y estoy mucho más fuerte, pero no creas hago el valiente porque no me muevo aun del cuarto, como ya te decia ayer.

María ha comido hoy conmigo y me encarga te salude, lo mismo que Morera, la Serrahima, el Señor Tesorero ha estado hoy aquí, y los papás.

Aunque no sean más que dos lineas escribeme todos lo dias papá, primero para saber de tí y luego por el alegron que tengo al ver letra tuya, por la mia ya conoceras voy adquiriendo fuerzas, pues la mano apenas me tiembla ya.

Mañana el Señor Tesorero hará decir á las once un oficio á San Magin ${ }^{8}$ en acción de gracias por haberme devuelto la salud.

Cuidate mucho papá, porque ya sabes que para mi la mejor noticia es saber que tu estas bien contento y tranquilo y con recuerdos afectuosos de mi marido, no dudes nunca del inmenso cariño que te tiene tu hija que te abraza una y mil veces.-Maria Elisa

A Alvaro expresiones y que deseo verle.

\section{CARTA NÚMERO 6}

Tarragona 9 de Enero de 1888.- Mi muy querido Papá: por tu grata de anteayer veo continuas bien; yo tambien lo estoy y hoy he dado ya dos ó tres paseitos por el cuarto yendo sola. Apetito no me falta. Hoy ha venido Mir y dice que contínuando así, saldré de casa el día de la Purificación ${ }^{9}$.

\footnotetext{
- Patrón de Tarragona.

${ }^{9}$ El 2 de febrero.
} 
No se porque leiste entre lineas en mi carta del $3^{10}$, que no me encontraba bien ó que no estaba de humor. Afortunadamente te equivocaste porque mi salud se puede llamar ya buena y no tengo motivos de mal humor sabiendo que la tuya tambien lo es.

Hoy he tenido compañia todo el dia. Por la mañana la Serrahima y el tesorero, á quien he dado la carta que adjuntaba la tuya y me ha dicho te escribiria esta noche. Tambien han venido los Marqueses de Vallgornera que han preguntado primero si tu estabas: yo no los he visto, los ha recibido Fernando y por la tarde Gracia, las Canals, Morera y el tio, todos me han encargado te saludara.

No subo aun sola á la cama, pero para bajar ya me puedo ayudar algo. En cuanto al arreglo de mi cabeza, figurate si estará enrredado el pelo, que hace seis dias que viene la peinadora y no tengo bien mas que los de delante.

Recuerdos a todos y un millon de besos y abrazos que te envia tu hija que mucho te quiere.-María Elisa

CARTA NÚMERO 7

Tarragona 10 de Enero de 1888.-Mi muy querido Papá:-- Me he quedado hoy sin carta tuya, que Dios quiera no sea por motivo de salud. La mia es buena y de cada dia voy recobrando mas fuerzas tanto que ya me entretengo cosiendo un poco para distraerme, porque me canso de estar todo el día sentada.

Me dijo ayer Maria Antonia, le guardaras cabezas de peonia; yo le pedí de dalia lila que recuerdo ví en Savartés y son muy bonitas.

Hoy me ha dicho la Serrahima que tia Lola había estado aqui y que hace cuatro meses que murió su marido.

Cuando nos veremos papá, lo deseo tanto, pero á lo menos no me falten noticias tuyas y tu debes estar tranquilo respecto á mi porque estoy muy bien.

Recibe recuerdos de todos y mil y mil besos de tu hija que mucho te quiere y desea verte pronto.-María Elisa.

10 Esta carta falta. 
Tarragona 11 de Enero de 1888.-Mi muy querido Papá.-Por tu carta de anteayer veo con gusto que sigues bien, lo cual me ha confirmado hoy Febré que acaba de irse de aquí hace un rato. Yo continúo bien, he pasado buen dia, comido bien y por primera vez me he levantado sola de la cama; esto te probarà que tengo muchas mas fuerzas. Dice Mir que para la Purificación podré (D. M.) salir de casa y ojalá me dijera estaré entonces en disposición de ir a esa para tener el gusto de abrazarte.

Si dejan el aceite en el patio, que haremos de los barrales?

El Señor Tesorero me dijo que como yo tardaré aun en salir de casa, diría el oficio á San Magín, no fuese que se muriese con esa deuda.

Con las cartas que te envie encontré el billete de la loteria, que tal vez me diste para que se mirara la lista.

Todos me encargan te salude, incluso la Pepa, que agradece mucho tus recuerdos y con los mios á Alvaro y Antonio, te envia mil besos y abrazos tu hija que mucho te quiere.-María Elisa

Tarragona 12 Enero 1888.-Mi muy querido Papá.-Fernando que ha ido a Reus esta tarde me ha traido tu grata de hoy, que un joven le ha entregado en la estacion y dice que Pablo Viñas nos traerá el cajoncito, por el cual te doy las gracias.

Supongo habrás recibido hoy carta y la que faltó ayer, por las cuales veras continuo muy bien; ha venido hoy Piquer y han quedado con Rovira de venir un dia de estos con Mir para ver si se puede cerrar el vegigatorio, asi es que no debes pasar ningun cuidado por mí y si muchos por tí, sabiendote abrigar y no pillar aires y luego ir siempre acompañado. Antonio que cuide de cerrar bien las puertas.

Esta mañana he leido tu grata de anteayer, que contenia una de tia Emilia.

Hace ya dias que no llevo tu bata y bien sacudida y cepillada Antonio la guardó. Llevo una matiné de muleton que me abriga mucho. 
Esta mañana me ha visitado Paca Calvet y esta tarde la viuda Morera y su hermana la de Ferrer y Mary; me han encargado te saludara, así como Fernando, los papás, la Serrahima y la puticari ${ }^{11}$ y con mil besos y abrazos, recibe papá el inmenso cariño que te tiene tu hija.--María Elisa

CARTA NUMERO 10

Tarragona 13 de Enero de 1888.-Mi muy querido Papá.-El Pau me ha enterado del buen estado de tu salud y por él también sabrás tu que yo adelanto rapidamente en mi convalencia; he andado delante de él para que te lo dijera y creo yo que á no ser estos dichosos y fastidiosos medicos que no quieren cerrarme el vegigatorio, iria mucho mas fuerte; á no ser esto creo podría salir para la Purificación, pero si aun lo llevo no podra ser porque ningun vestido me vendría bien.

Fontana ha venido hoy á saber como seguía yo, pero como Fernando no estaba en casa, no lo he visto; á mi me hacian compañia Morera y mamá ${ }^{12}$, también ha venido el tío, que dice te ha escrito un día de estos.

Esperando tu carta de hoy y con recuerdos de Fernando, así como mios para Alvaro y Antonio y tu recibe mil y mil besos tu hija que mucho te quiere y desea verte pronto.-Maria Elisa

Tarragona 14 de Enero 1888.-Mi muy querido Papá.-Buen chasco me he llevado hoy cuando he visto que me quedaba sin carta tuya, aunque creo no tendrás novedad. Yo gracias á Dios continuo muy bien y ya voy engordando algo y subo y bajo sola de la cama; ya veras papá

"La boticaria, más probablemente que el boticario, en catalán: «apoticari», con o muy cerrada. Es la única palabra catalana en la correspondencia y está escrita incorrectamente, asimilando la a inicial al artículo femenino. La forma correcta sería "'apoticari», masculino, o "l'apoticaria", femenino.

${ }^{2}$ Se refiere a su suegra. 
como me vas á encontrar desconocida cuando me veas. Hasta cuando piensas estar en esa?

La viuda Fontanals y su hija, que han estado aqui esta tarde me han encargado te saludara, lo mismo que la Serrahima, el matrimonio Morera y el papá Querol.

Has probado ya el vino? Malas noticias dan por aqui, el Pau me dijo que opinaban que todavia bajaría mas.

Dice el Jaime, albañil, que se le debe la cuenta del mes de Junio, y que Antonio ya lo sabe. Dime si la tienes y podrías enviarla para que se pagara.

Recuerdos de Fernando y ya sabes papá cuanto te quiere tu hija que te abraza mil y mil veces.-María Elisa

Tarragona 15 de Enero 1888.-Mi muy querido Papá.-Dos días que no tengo carta tuya y ya ves que no cuesta mucho decirme como estas, porque dos renglones bastan y yo me quedo tranquila y contenta. Por mi ya lo puedes tu estar, porque gracias á Dios adelanto mucho en mi convalencia. Tengo buen apetito y muchas mas fuerzas. El Señor Tesorero, que me ha hecho compañía toda la tarde, ha quedado sorprendido al ver lo bien que ando. También han estado aqui esta tarde mamá, los Moreras y la Marquesa de Montoliu y sus hijas y al despedirse me ha dicho la madre que ya que recibo vendrán á hacerme compañia.

Por la mañana ha venido Paco Brú. La pobre Carolina estando en Tortosa fué a casa de un dentista á que le sacara una muela y fué tan barbaro que no solo le quitó la muela sino que le hizo seguir un pedazo de hueso, así es que la pobre está en cama con calentura.

Ya tengo desenredado el pelo, pero como no estoy aun en disposición de peinarme yo seguirá viniendo la peinadora.

Recibe recuerdos de todos y deseando tener buenas noticias tuyas te abraza y besa una y mil veces, tu hija que mucho te quiere.-María Elisa 
Tarragona 16 de Enero de 1888.-Mi querido Papá; por fin recibo hoy tu grata de anteayer que me ha tranquilizado respecto á tu salud porque temia que el quedarme dos días sin carta, fuera por no estar tu bien. Yo ya no puedo desear más, porque de cada día me encuentro con muchas mas fuerzas, afortunadamente ya puedo vestirme sola, ando muy bien y subo y bajo sola de la cama. Si tuviera á la niña podríamos estar mas que contentos porque no creía yo reponerme tan pronto; pero cuanto mas distraida no estaria si ella viviera. de dalia.

He cumplio tu encargo para Rovira y dice que me dará las patatas

Si han recibido varios las targetas y esta noche hemos recibido la de la familia Muller; también te han enviado a ti.

No pases cuidado por mi, no salgo del cuarto mas que al tocador. Tu si que debes cuidarte y guardarte de los aires y mas en estos días humedos.

Recibe recuerdos de todos y te abraza una $y$ mil veces tu hija que mucho te quiere.-María Elisa

Tarragona 17 de Enero de 1888.-Mi querido Papá.-Tambien hoy me he quedado sin carta tuya, espero la tendré mañana.

Yo sigo muy bien, a pesar del mal tiempo que tenemos, lo unico que me fastidia es el vegigatorio, que todavia mana un poco, pero creo lo cerraran un dia de estos.

No te envio la damajuana de vino, porque como yo sola la bebo, queda aun, si acaso la daré al mozo.

Son las ocho de la noche, ya he cenado y llega en este momento Rovira que viene á curarme. Recibe recuerdos de todos y un millón de besos y abrazos de tu hija que mucho te quiere y desea verte.-Maria Elisa 
Tarragona 19 de Enero de 1888.-Mi muy querido Papá.-Tampoco hoy he tenido noticias tuyas y como hace ya tres dias que no tengo carta y el tio tampoco sabe nada estoy con cuidado. Porqué no me escribes, estás enfermo, ó que tienes? Dime la verdad Papá.

Yo continuo bien, esta mañana ha venido Piquer y dice que es de opinion de cerrar el vegigatorio. Veremos que dirá Mir que hace dias que no me ha visto. A pesar de encontrarme bien no salgo de mis habitaciones porque temo resfriarme y mas con el tiempo tan humedo que hace.

Esta tarde han venido un tal Antonio Magriña y Sunyer que dice te escribirá.

He recibido hoy los vestidos negros, muy sencillos y elegantes y el sombrero es una bonita capota de terciopelo negro, con un pajaro café y plumas crema.

Cuidate mucho papá; primero eres tu que nada para tu hija que mucho te quiere y abraza mil veces.-María Elisa

Los papás y Fernando te saludan. Dice Rovira que probablemente el sábado ó domingo irá a esa para hablarte de un asunto que cree no lo tiene muy bien.

Tarragona 24 de Enero de 1888.-Mi queridisimo Papá.-Con hoy tres dias que no tengo carta tuya ya ves que es bien poco poner dos renglones y yo me quedaria tranquila. Por mi puedes estarlo porque sigo muy bien. El vegigatorio se me ha cerrado hoy por si solo. Mir tenia que venir ayer, debe estar enfermo porque no ha venido, y á Rovira hace cuatro dias que no le hemos visto.

Esta tarde he tenido una alegria. Ha venido a verme Mosen Ramon; muchas cosas para ti me ha encargado y dice que solo ha venido a Tarragona para verme.

Ahora me tienes de mal humor porque digeron los Moreras que me traerían al nene y no viene. Me distraigo con él y me parece que tengo a la niña, esta muy robusto y es muy guapo. 
Memorias de Puigcerver que ha estado aqui y ha dicho venias a ultimos de mes.

Adios papá hasta mañana, cuidate mucho y no dudes del intrañable (sic) cariño que te tiene tu hija que mucho te quiere y desea abrazarte.--María Elisa

Tarragona 25 de Enero 1888.-Mi muy querido Papá.-Por tu carta de anteayer veo sigues bien de salud, que es lo que yo pido á Dios todos los dias. La mia es ya completamente buena y cuando me veas veras como no se me conoce haya estado enferma. Como te decia ayer el vegigatorio se ha cerrado y hace cinco dias que no me ha visto ningun medico debido a la grave enfermedad de Mir á quien confesaban ayer pero como luego desaparecio un poco la gravedad no le dieron el Viatico.

El aceite no lo hemos empezado todavia. Las nueces son muy buenas.

La Pepa desea le envies una carta para Masallas que le podria presentar un sobrino.

Mi marido, los papás y los Moreras, que han estado con el niño, me encargan te salude y recibe un millon de besos de tu hija que te quiere mas que á su vida.-María Elisa

CARTA NUMERO 18

Tarragona 26 de Enero de 1888.-Mi queridisimo Papá.-Aunque no he recibido carta tuya supongo sigues sin novedad Dios lo quiera y asi se lo pido todos los dias. Yo continuo muy bien y si es verdad que estoy mas delgada tengo tan buen color como antes de estar enferma y ya te he dicho otras veces que cuantos me ven se hacen cruces me haya repuesto tan pronto de una enfermedad tan larga y pesada.

Fernando ha salido hace un rato para ir al Viatico del Señor Mir, el pobre está muy grave los medicos desconfian salvarle.

Hoy ha venido á verme la Marieta de la Torre; me ha preguntado mucho por ti, encargandome te saluda (sic). Por la tarde me han visitado 
el matrimonio Ramonacho y las Sunyeras, haciendome todos igual encargo.

Escribeme papá y dime como estás cuidate mucho y con recuerdos de mi marido y papás, te envia un millon de besos y abrazos tu hija que mucho te quiere.-María Elisa

Tarragona 27 de Enero 1888.-Mi querido Papá; por tus cartas 25 y 26 veo continuas bien de salud que es lo que á mi mas me interesa en este mundo y no solo aspiro á que vivas en el resignado como tu dices sino hasta feliz si es que existe la felicidad. Yo lo seré si se que tu estas bien y convencido que sabre siempre cumplir mi deber contigo y con $\mathrm{mi}$ marido; asi es que entre nosotros no habrá el alejamiento que dices, porque yo estaré siempre á tu lado cuando me necesites.

Por el Pau y el alcalde de la Vilella sabrás que estoy muy bien, así es que ya debo estar de alta, porque aunque no me hayan dado los medicos, hace dias que no los he visto y yo gracias a Dios estoy perfectamente.

Me han visitado hoy las Canals, Manuela Romeu y Mosent Morlá que me han encargado te saludara.

Ya sabrás que el pobre Mir ha fallecido hoy a las dos de la madrugada.

Cuidate mucho papá y vive para ti, y cuenta siempre con el inmenso cariño que te tiene tu hija que te abraza una y mil veces.-María Elisa

Tarragona 28 de Enero 1888.-Mi muy queridisimo Papá.-Si no fuera por seguir la costumbre no tendria ya que hablar de mi salud, porque mi enfermedad paso a la historia y ya estoy tambien como antes; pero como evito toda recaida, no salgo aun de mis habitaciones. Dios quiera que tu estes como yo.

Ayer tuve carta de tia Emilia y de Cárlos, nos invitan á pasar una temporada con ellos. 
Mañana, D.M., contestaré a tio Ernesto.

Con la enfermedad y muerte del pobre Mir (q.e.p.d.) hace una porcion de dias que no he visto á los medicos. Ayer me ofrecio Piquer venir y esta es la hora que le espero para saber si tengo que ponerme la tintura yodo, aunque yo creo que no hace falta porque estoy muy bien y aunque se me apriete el viente no me hace daño.

Recibe mil recuerdos de todos y un millon de besos y abrazos de tu hija que mucho te quiere.-María Elisa

Tarragona 29 de Enero de 1888.-Mi muy querido Papá.-A pesar de no recibir carta tuya hace dos dias, supongo que no tienes novedad. Yo continuo muy bien y creo que si el tiempo mejora pronto podré ir á misa.

Aqui se deja sentir bastante el frio, tal vez á causa del viento que hace; y como supongo que en esa los dias no deben ser muy buenos, abrigate y cuidate papá no sea que pilles alguna enfermedad.

Mañana son los funerales del Señor Mir y como ayer se fué á Reus el papá Querol en este momento va Manuel para avisarlo, por si quiere asistir. Así es que no puedo estenderme mas. Recibe recuerdos de todos y mil y mil besos de tu hija que mucho te quiere.-Maria Elisa

\section{CARTA NÚMERO 22}

Tarragona 17 de Agosto de 1893.-Al Excmo. Sr. Conde de Rius.-Muy estimado Sr. Conde.-Ya sé que este año no recibe $V$. felicitaciones por sus dias, pero esto no ha de ser para mi motivo para dejar de escribirle aunque no sea mas que para saludar á $V$. y recordarle que pido y pediré al Señor que por intercesion del Sts. Martir su patron se digne conceder a $\mathrm{V}$. buena salud y toda la conformidad necesaria para llevar bien todas las penas que sobre $\mathrm{V}$. pesan.

Yo no olvidando á la pobre María Elisa y creyendo interpretar los buenos deseos de $V$., quiero que ella participe de la fiesta, á cuyo fin tengo reservada para ella la Sta. Misa del dia 19, y ella desde el cielo, 
donde la supongo yá disfrutando el premio de sus virtudes, rogará por $V$., esposo, hijos y para los buenos amigos que aqui le quedaron.

Deseo que $V$. siga bien y que se cuide mucho, yo hace una porción de dias que estoy molestado del dolor que me hace pasar muy malas noches, pero gracias á Dios, me permite salir de casa y asistir á coro.

Salude a la Pepa y Albaro (sic), y disponga V. como guste de su affmo. S.S. y C. Q.B.S.M. - Francisco Escudé. 